\title{
UM OLHAR VERDE SOBRE AS RUAS E ROTUNDAS DE COIMBRA*
}

\author{
António Campar de Almeida**
}

Ouvem-se por vezes algumas vozes dizer que a cidade de Coimbra tem poucos espaços verdes. No entanto, no perímetro urbano da cidade, contam-se quatro parques, com alguns deles a estenderem-se por um espaço razoável, em proporção com a extensão do aglomerado, e com a vantagem suplementar de ocuparem uma posição central: o Parque de Sta Cruz, vulgo Jardim da Sereia, o Jardim Botânico, o Parque do Penedo da Saudade e o Parque Manuel Braga. Estas áreas arborizadas podem fácil e abertamente ser usufruídas pela população que o desejar, com excepção do Jardim Botânico onde apenas uma parte pode ser visitada.

Mesmo no núcleo antigo da cidade, na chamada "Alta", por trás de muitos dos prédios, cuja disposição desenha ruas estreitas e tortuosas, são frequentes os "quintais" onde, para além das hortinhas, há sempre um grande número, para o espaço disponível, de árvores de fruto ou de ornamentação, que equilibra pelo verde a densa ocupação humana.

Penso que essa sensação de falta de espaços verdes advém mais da fraqueza, e por vezes falta, de cobertura verde das ruas da cidade, do que propriamente da inexistência de parques onde as pessoas possam ir passear nos seus tempos livres. Até porque não parece haver grande tradição dos citadinos de Coimbra em passarem muito tempo nestes espaços. Contudo, onde passam uma boa parte do seu dia a dia é a percorrer os corredores da cidade, nas suas deambulações quotidianas, ora em direcção aos seus postos de trabalho, ora para outros pontos pelos mais variados motivos, ou seja as ruas e avenidas da cidade. Quer o percurso seja feito a pé, de autocarro, ou de automóvel, é muitas vezes penoso fazer certos trajectos em dias de calor, tão frequentes no Verão, assim como em alguns períodos da Primavera e do Outono.

É certo que a cidade se expandiu muito nos últimos anos, com a concomitante abertura de novas ruas e avenidas onde não houve ainda tempo de se verificar um desenvolvimento suficiente das árvores plantadas, de modo a ser alcançada a sombra desejada; mas, estará essa

* Projecto PRAXIS XXI - n. ${ }^{\circ}$ 2/21/CTA-156/94.

** Instituto de Estudos Geográficos. Faculdade de Letras. Universidade de Coimbra. arborização a ser feita de maneira equilibrada e ecologicamente razoável?

\section{As ruas}

As árvores nas ruas, para além da sua componente de embelezamento, que deve ser sempre salientada, desempenham outras funções não menos importantes no tecido urbano. Um deles é o de ajudarem à despoluição do ar, cada vez mais carregado de gases nocivos largados em escala crescente, com o aumento da circulação automóvel, muitas vezes feita em situação de congestionamento. Um outro é o de refrescar, pela sua sombra e evapotranspiração, aqueles corredores que, pela reflexão das paredes e pela côr escura do pavimento, construídos com materiais de rápida condução calorífica (A. B. COELHO e A. R. CABRITA, 1986), funcionam como autênticos emissores de calor, nos dias da canícula, em tantos dias do ano nesta cidade. Todas as sombras existentes não são de mais nesses períodos. Também funcionam como barreiras acústicas, amenizando o ruído emitido pela circulação automóvel e audível dentro das habitações (I. BOVET PLA, 1995).

Tendo em atenção estes aspectos aparentemente relevantes, é de supor que todas as artérias da cidade, com excepção das ruas estreitas da parte antiga (Alta e Baixa), estejam cobertas por árvores mais ou menos frondosas. Sabe-se, porém, que nem sempre é isso o que se passa. Ainda há ruas relativamente largas e com passeios espaçosos onde não se vê uma árvore; mesmo nas ruas e avenidas novas não se consegue discernir, por vezes, qual a lógica que presidiu à arborização encetada.

Vou analisar apenas alguns casos a título de exemplo.

Entre as ruas não arborizadas, parcial ou totalmente, e onde seria fácil fazê-lo, podem citar-se a Rua Antero de Quental e a Rua de Aveiro, por onde se processa grande parte do escoamento do trânsito a partir da Universidade. Na própria Universidade, com excepção da rua entre as Faculdades de Medicina e de Física, a sensação que se tem é de se estar num descampado de aspecto árido, tal a quantidade de superfícies nuas a reflectirem radiação solar.

Talvez mais grave é quando se trata de ruas recentes, como a Rua Afrâneo Peixoto, agora integrada na Circular 
Interna, que não tem uma árvore. Mas esta circular, maioritariamente constituída por duas faixas de rodagem em cada sentido, com separador central, apresenta aspectos curiosos nos critérios seguidos para a sua arborização: na maioria dos casos tem árvores nos dois passeios laterais, noutros tem apenas em um dos passeios e chega a ter, em alguns troços, árvores nos passeios e no separador central. Por que não plantar sempre nos três sítios possíveis? Se o separador não é suficientemente largo, fizessese mais largo para poder suportar aquelas plantas. As avenidas, amplas como são, só têm a ganhar em equilíbrio estético e em sombra com as três linhas de árvores.

As espécies escolhidas ou a escolher também merecem uma referência. Tem-se optado, a maioria das vezes, por espécies exóticas que em certos casos não parecem estar adaptadas às condições ecológicas da cidade, ou sofrem mais o efeito da poluição citadina, ou então não respondem aos fins enunciados anteriormente.

A chamada Flor-da-Merenda (Lagerstroemeria indica L.) é uma dessas plantas que, pelo seu porte demasiado pequeno e ainda por cima, nas ruas de Coimbra, com uma folhagem rara e por vezes irregular, quase não fornece sombra digna de referência. As ruas Oliveira Matos, Castro Matoso e Alexandre Herculano, por exemplo, têm os passeios em grande parte ocupados por esta espécie. A falta de sombra é notória.

Em contrapartida, na mesma área, na rua Venâncio Rodrigues, as plantas, apesar de serem de porte semelhante, ou seja arbustivo, já apresentam uma fronde mais exuberante, aliada à profusão, no tempo próprio, de flores de razoável tamanho, agradáveis à vista e ao olfacto, e dão um aspecto menos árido à rua do que a espécie anterior. A planta em causa é o Hibisco-da-Síria (Hibiscus syriacus L.), arbusto mediterrâneo que pode adquirir porte subarbóreo, desde que orientado para isso, como é o caso.

Outra espécie que parece não ter tido grande sucesso como árvore de rua, é a Robínia ou Acácia bastarda (Robinia pseudacacia L.). Pelo menos em ruas como as avenidas Dias da Silva e D. Afonso Henriques elas apresentam-se decrépitas, com fronde muito irregular e rara, a exercerem mal as funções para as quais foram destinadas. É possível que seja um problema de idade, necessitando, portanto, de ser renovadas; seja como for, talvez não fosse má ideia proceder à sua substituição por outras mais frondosas e, eventualmente, melhor adaptadas ao local.

Nas avenidas amplas recentes, as espécies a escolher para os passeios laterais deveriam ser árvores de grande porte, tanto mais quanto se pensar em não arborizar o separador central. Ora, salvo algumas honrosas excepções como por exemplo a avenida Mendes Silva, ladeada por plátanos e por liquidâmbares (Liquidambar styraciflua
L.), a espécie mais utilizada tem sido a conteira (Melia azedarach L.), uma árvore interessante, de flores aromáticas, frondosa, mas, de facto, de porte modesto.

Outro aspecto que é de estranhar é a pouca frequência com que são plantadas árvores da nossa flora, em especial as mais típicas desta região centro litoral as que, à partida, estariam melhor adaptadas. Exceptuam-se as ripícolas como o choupo (muitas vezes espécies híbridas), o freixo e o ulmeiro, em regra com bom sucesso. Já este ano, foram plantadas oliveiras num talude do viaduto de Santo António dos Olivais, sinal, porventura, de que algo está a mudar em termos de filosofia de arborização dos arruamentos da cidade.

O rebaixamento das árvores com cortes intensos, mesmo ao nível do tronco principal, é outra prática que até há alguns anos era usual nesta cidade. Felizmente que nos últimos anos, essa "chaparrização" das árvores de Coimbra tem sido menos frequente, talvez por finalmente terem sido escutados os protestos de alguns especialistas e de outros cidadãos, mais sensíveis àqueles atentados à estética própria de cada árvore. Por que razão hão-de todas as árvores folhosas apresentar uma forma arredondada e baixa, quando algumas têm a tendência para serem esguias e altas? Se se pretendem baixas e redondas, escolham-se as que adquirem, espontaneamente, essa forma, e há várias...

Quando muito, penso que, para além de uma poda inicial de formação - a qual também pode ser discutível porque as árvores quando isoladas desenvolvem copas mais largas do que quando em agrupamento - as únicas podas a efectuar deverão ser as que retiram as partes das árvores que estejam a perturbar qualquer equipamento, edifício ou as pessoas, ou então que estejam em risco de cair. As grandes podas efectuadas sobre os plátanos da Avenida Emídio Navarro, da Avenida Sá da Bandeira e da Praça da República, só para dar estes exemplos, parecem totalmente despropositadas, atendendo ao espaço amplo onde aquelas árvores estão inseridas.

Mesmo nos jardins ou parques, essa acomodação das árvores a formas predeterminadas é discutível. Se é certo que essa prática corresponde a um modelo de jardim do início do século, com uma disposição geométrica das árvores, com alguma simetria de espécies, com formas condicionadas, sempre que possível semelhante e de que o Parque Manuel Braga é um exemplo ilustrativo, penso que neste momento não se justifica a manutenção desse status em função dos novos paradigmas vigentes. Um jardim é sempre um espaço artificializado, em maior ou menor grau, sendo essa artificialização, no primeiro caso, manifestada pelo próprio desenho inicial dos espaços que o compõem: os destinados ao passeio das pessoas, os 
destinados às plantas, onde se incluem ou não árvores, sendo estas quase sempre espécies escolhidas. Ora, a manutenção do estilo inicial de jardim já deveria partir dessa mesma escolha das espécies - as de menor porte e de fronde fechada onde se pretende um espaço mais recatado, as de maior porte e/ou de fronde menos fechada onde se pretende um espaço inferior aberto. Em todo o caso seria de evitar ao máximo as intervenções por vezes traumatizantes que se fazem sobre as árvores, deixandoas desenvolverem-se, ao menos na vertical, livremente. Nem sequer é novidade na cidade - no Jardim Botânico assim acontece.

\section{As rotundas}

Desde há alguns anos que têm vindo a ser construídas rotundas nesta cidade, com o intuito, não sei se sempre eficaz, de melhorar o escoamento do trânsito nas ruas de maior circulação automóvel. O seu número já se conta pelas dezenas e a sua dimensão é bastante variada, podendo o espaço central ajardinado ter entre poucos metros e mais de trinta metros de diâmetro. Ora, é precisamente sobre o tipo de ajardinamento que tem sido praticado que vou tecer algumas considerações.

Em regra, aquele espaço é arrelvado e é entremeado por alguns canteiros de flores (espécies herbáceas) ou com arbustos (normalmente exóticos) e/ou aqui e além algumas árvores. Diga-se que o resultado final é agradável e de um certo bom gosto, mas a que preço se mantém este tipo de espaços verdes? A relva exige, no período quente e seco, que é em Coimbra de cerca de quatro meses, sem contar com alguns anos em que a estiagem pode ocorrer em períodos não usuais ${ }^{1}$, uma ou duas regas diárias, para se manter verde. $\mathrm{O}$ mesmo se passará com boa parte das flores de canteiro usadas. A alternativa óbvia penso que seria a utilização de plantas menos exigentes em água, mais de acordo com as condições ecológicas desta cidade, ou seja, adaptadas a esta secura estival que é, decerto, o factor ecológico mais limitante.

Nem sequer é necessário pensar muito para se concluir sobre as espécies a escolher para as rotundas, basta percorrer, no Verão, os campos das regiões centro e sul do nosso país e aí estão elas, mantidas verdes, apesar das

'É perfeitamente normal nas regiões com clima mediterrâneo, como é o caso de Coimbra, haver essa variabilidade interanual no regime de precipitações. Este ano de 1997 é um desses exemplos, com Março sem qualquer precipitação e com a maior parte dos dias quentes, com temperaturas máximas acima dos $25^{\circ} \mathrm{C}$ e a humidade relativa muito baixa. Nalgumas rotundas mevia relva seca. condições ambientais agrestes, em especial da secura do meio. São, em regra, plantas lenhosas, conhecidas, na maioria, por fruticosas e que têm a vantagem de se distribuírem por diferentes estratos de vegetação. Apenas a título de exemplo, podiam escolher-se tomilhos (Thymus spp.), rosmaninhos (Lavandula spp.), algumas Cistáceas como Cistus spp. ou Halimium spp., o alecrim (Rosmarinus officinalis L.), a murta (Myrtus communis L.), o folhado (Viburnum tinus L.), plantas dos estratos herbáceo, subarbustivo e arbustivo que têm a vantagem de serem quase todas elas aromáticas, logo, simultaneamente agradáveis pela vista e pelo cheiro. Além disso, estes aromas fazem despertar, às pessoas que há muito deixaram as suas aldeias, recordações de outros tempos e lugares e, de certo modo, reencontrarem as suas raízes, ou seja, o seu ser mais profundo. Para as pessoas nadas e criadas na cidade, e pouco afeitas a deambulações pelo campo, proporcionar-lhes-iam um contacto com uma realidade que, decerto, reconheceriam ser gratificante.

Quando as rotundas são de maiores dimensões, por exemplo com 30 ou mais metros de diâmetro, como é o caso da situada entre os hipermercados Makro e Continente, talvez não fosse má ideia instalar um bosquete com árvores também autóctones, bem adaptadas ao meio e que, para além das razões apontadas para os arbustos e subarbustos, criariam um ambiente de sombra e de frescura no Verão. As espécies seriam as típicas desta região, o carvalho-cerquinho (Quercus faginea Lam.), o sobreiro (Quercus suber L.), o azevinho (Ilex aquifolium L.), o medronheiro (Arbutus unedo L.), um ou outro carvalho mais do norte, como o alvarinho (Quercus robur L.), etc. Têm a vantagem de serem árvores não muito altas - é raro atingirem os $20 \mathrm{~m}$ - e de serem relativamente longevas.

A ideia de pôr árvores nas rotundas é uma prática usual noutras cidades do país. Por exemplo em Viseu, ainda há pouco tempo uma rotunda foi redesenhada, de modo a poder incluir uns carvalhos alvarinhos seculares existentes no local e que a edilidade achou por bem, e muito bem, não deitar abaixo. Cá em Coimbra, salvo raras excepções, como é o caso de alguns belos exemplares de sobreiros mantidos no Bairro Norton de Matos, não se tem visto seguir o mesmo critério - o Vale das Flores é talvez o caso mais saliente e actual, pois tudo foi arrasado e construído.

\section{CONCLUSÃo}

É possível criar um ambiente mais agradável na cidade de Coimbra, para as pessoas que circulam nas suas ruas, aumentando a sua arborização, quando necessário, 
ou então escolhendo as espécies melhor adaptadas, quer às condições ecológicas, quer às dimensões do arruamento. As intervenções nas copas das árvores devem ser reduzidas ao mínimo, o indispensável para evitar eventuais transtornos. $\mathrm{O}$ interior das rotundas deveriam ser ajardinadas ou arborizadas com espécies autóctones; poderiam ficar mais dispendiosas na instalação, mas no futuro, com a redução drástica nas necessidades em água e em mão-de-obra, para além do resultado final ser mais equilibrado com a natureza e com o homem, compensariam sobremaneira esse investimento inicial.

\section{REFERÊNCIAS BIBLIOGRÁFICAS}

Bovet Pla, Isabel (1995) - "Usos y funciones de los vegetales en zonas urbanas”. Geórgica, 4, 189-201, Huesca.

Coelho, A. J. M. Baptista e CABritA, A. M. Reis (1986) Estudos sobre espaços exteriores em novas áreas residenciais. Doc.-Base 4. Qualificação de espaços exteriores de uma nova área residencial. L.N.E.C., Inf. Téc., Arquitectura e Urbanismo DIT 21, Lisboa. 